\title{
Sources of metasilicate in mineral water of Jingyu County, northeastern China
}

\author{
Changlai Xiao ${ }^{1}$, Yajie Yuan ${ }^{1}$, Xiujuan Liang ${ }^{1, *}$,Weifei Yang ${ }^{1}$, and Ying Sun ${ }^{1}$ \\ ${ }^{1}$ Key Laboratory of Groundwater Resources and Environment, Ministry of Education, Jilin \\ University, No 2519, Jiefang Road, Changchun130021, PR China
}

\begin{abstract}
The source of metasilicate in mineral water of Jingyu County. located in Changbai Mountains of northeastern China, was analysed through two groups of water-rock interaction experiments. One is a hydrolysis immersion experiment using basalt and the other is an immersion experiment utilizing a mixture of soil, scoria, and clastic basalt under the same conditions. Results indicate that the metasilicate in mineral water is mainly derived from the hydrolysis of silicates and silica in the basalt, scoria, and soil. In the first immersion experiment, the release of metasilicate is linear, with dissolved metasilicate increasing continuously through time at a stable release rate of about $0.01 \mathrm{mg} /(\mathrm{kg} \cdot \mathrm{day})$. The second experiment indicates that the contribution of soil and scoria to metasilicate in mineral water is higher than that of clastic basalt under the same conditions.
\end{abstract}

\section{Introduction}

Many studies on hydrogeochemical characteristics of groundwater and on water-rock interactions have been conducted by different scholars [1-4]. Natural mineral water has attracted much attention due to its special components that are beneficial to our health [2-4]. Changbai Mountains is one of the three largest natural mineral water sources in the world, comparable to the Alps and the North Caucasus mountains. It is also a source of mineral water, with a large area of $16,300 \mathrm{~km}^{2}$ covered with basalt.

The characteristic component of Jingyu County natural mineral water is metasilicate, and its content is normally $30-49 \mathrm{mg} / \mathrm{L} \mathrm{[5]}$. The interpretation of geophysical exploration and drilling from the view of hydrogeology shows that thickness of the basalt in Jingyu County is less than $150 \mathrm{~m}$, and the lower part is the Neogene mudstone and sandstone with a thickness of less than $50 \mathrm{~m}$, which is in turn underlain by the Archean metamorphic rock stably distributed and forming a water-resistant floor in the area. This floor constrains the deep circulation of groundwater and indicates that natural mineral water is formed by the circulation of shallow groundwater [6].

This study was carried out to determine the source of metasilicate in mineral water of Jingyu County through two hydrolysis immersion experiments, the first using basalt and the second a mixture of soil, scoria and clastic basalt under the same conditions.

\footnotetext{
* Corresponding author: lax64@126.com
} 


\section{Study area}

Jingyu County, which covers a total area of $3094 \mathrm{~km}^{2}$, is located in the southeastern region of Jilin Province of northeastern China. The area is characterized by a humid, temperatecontinental climate. The average annual temperature of the region is 2.5 to $3.0^{\circ} \mathrm{C}$ and the average annual precipitation is 750 to $850 \mathrm{~mm}$.

A150 m deep scientific experimental well was drilled in 2013 [6]. The results showed that the subsurface stratigraphy consists primarily of Neogene olivine basalt, augitophyre and stomatal basalt, Quaternary Pleistocene stomatal basalt and olivine basalt, Miocene stomatal basalt and olivine basalt, and Holocene clinopyroxene olivine basalt.

The analysis and determination of oxides in basalt at different locations across the study area shows that the silica contents of the basalts is around $50 \%$, with a coefficient of variation of only 0.028 [7]. This silica is thought to be the most likely source of metasilicate in natural mineral water.

The scoria in Jingyu County is homologous to the basalt with same ages, and it consists of similar mineral and chemical components. The surface layer of basalt in the study area is widely distributed with Baijiang soil (similar to mollicplanosol), which is about $20-30 \mathrm{~cm}$ thick. The parent material of the soil mostly consists of basalt and scoria weathering residue, in which basalt debris accounts for 45 to $72 \mathrm{wt}$. \% [6].

\section{Hydrolysis and immersion test of nubby basalt}

In order to explore the source of metasilicate in the mineral water of Jingyu County, we designed a hydrolysis and immersion test in the lab, which simulating the interaction between water and rock under the state of static water flow conditions.

\subsection{Experimental plan}

Two rock samples were collected from the scientific experimental well, at the depth of 6769 and $80-83 \mathrm{~m}$, and cut into two cubes of $1.5 \mathrm{~cm}$ in length, $0.35 \mathrm{~cm}$ in height and $1.4 \mathrm{~cm}$ in width. These two cubes were labeled as $\mathrm{Q}_{6}$ and $\mathrm{Q}_{7}$, and weighed at $24.1 \mathrm{~g}$ and $25.4 \mathrm{~g}$, respectively. Then, deionized water was added at a water/rock ratio of 5:1, the vessels were sealed with a cover and stored at room temperature (about $20^{\circ} \mathrm{C}$ ), and then $25 \mathrm{~mL}$ samples from the water/rock solution were collected after $3,6,10,15,20,25,30,40,60,80,100$ and 120 days. An equal volume of deionized water was added to the vessel after sample extraction to maintain a constant fluid level. The metasilicate in the samples (as dissolved metasilicic acid in $\mathrm{mg} / \mathrm{L}$ ) was determined using Silicon Molybdenum Yellow Spectrometry, then the release amount of metasilicate $(\mathrm{mg} / \mathrm{kg}$ ) was calculated by dividing the mass of total metasilicic dissolved in solution by the mass of basalt.

\subsection{Results and discussion}

Metasilicate was continuously released with time, and its content in water kept increasing (Fig. 1). The release amount of metasilicate has reached $1.027 \mathrm{mg} / \mathrm{kg}$ and $1.312 \mathrm{mg} / \mathrm{kg}$ within 120 days, for $\mathrm{Q}_{6}$ and $\mathrm{Q}_{7}$ respectively. A linear relationship can be noticed between the released amount of metasilicate from basalt and time. The fitting functions of basalt collected from different positions are slightly different, but the release patterns of metasilicate are basically the same. As time went on, the metasilicate content in groundwater kept increasing as the fitting function of $y=a x+b$ (correlation coefficient $r^{2}>$ 
0.965). Statistical significance analysis using the F-test shows a significant correlation at the significance level of 0.01 .

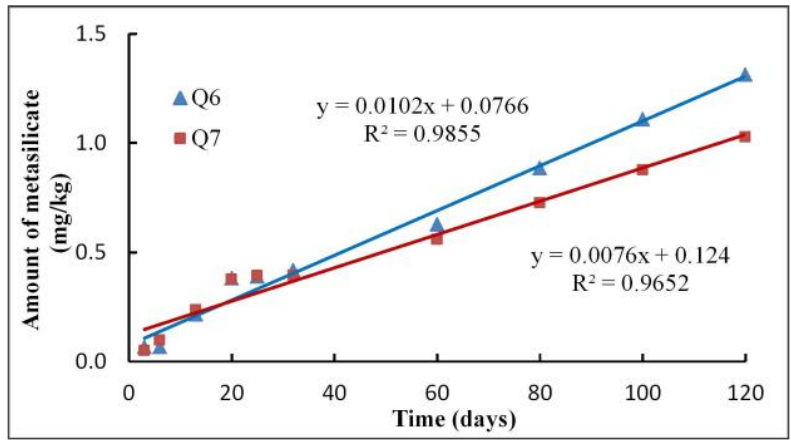

Fig1. The relationship between the release amount of metasilicate and time.

The release rate of metasilicate (the amount of metasilicate released into water per kilogram of basalt per day) was calculated according to the relationship:

$$
v_{i}=G_{i} /\left(t_{i}-t_{i-1}\right)
$$

where $v_{i}$ refers to the average release rate on the $i^{\text {th }}$ sampling $\left(\mathrm{mg} \cdot \mathrm{kg}^{-1} \mathrm{day}^{-1}\right) ; \mathrm{t}_{\mathrm{i}}$ refers to the time of $i^{\text {th }}$ sampling (day); $\mathrm{t}_{\mathrm{i}-1}$ refers to the time of the (i-1)th sampling (day); and $\mathrm{G}_{\mathrm{i}}$ refers to the amount of metasilicate $(\mathrm{mg} / \mathrm{kg})$ released from the $i^{\text {th }}$ to the $(\mathrm{i}-1)^{\text {th }}$ sampling. The release rate of metasilicate was obtained using Equation (1). The relationship between the release rate of metasilicate and time is plotted in Figure 2. We observed that the release rate fluctuates at the beginning of the experiments, due to both a high release rate and frequent water exchange. As time goes on, the release rate gradually tends to be stable and remains constant at the end of the experiment. The experimental results indicate that the constant release rate of metasilicate is about $0.01 \mathrm{mg} /(\mathrm{kg} \cdot \mathrm{day})$.

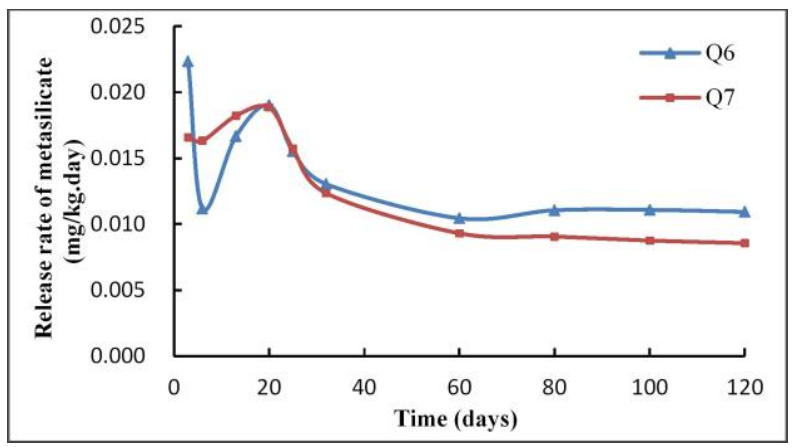

Fig. 2. The relationship between the release rate of metasilicate and time.

Based on this analysis, we infer that $\mathrm{SiO}_{2}$ in the basalt is continuously released into the solution, with the effect of lixiviation and hydrolysis process after immersion. In this way, the metasilicate is acquired by the natural mineral waters of Jingyu County.

\section{Immersion test of scoria, soil and clastic basalt}

A second experiment was undertaken to further understand the contributions and differences in mineral water metasilicate produced by soil, scoria and basalt. 


\subsection{Experimental details}

The experimental medium was a mixture of soil, scoria, and basalt collected in the volcanic region of Jingyu County. Deionized water was used as an immersion solution. The basalt was ground to particles of a size similar to that of the scoria ( $\sim 1$ to $2 \mathrm{~cm})$. According to the coning and quartering method, the soil, scoria and clastic basaltic were divided into 20 portions, respectively, each weighing $500 \mathrm{~g}$. Each aliquot of the three portions was separately placed into a different experimental vessel, with a solid/liquid ratio of 1:5. All vessels (a total of 60 vessels in 20 groups) were sealed with covers and stored at room temperature (at about $20^{\circ} \mathrm{C}$ ). The sampling time interval of the 20 groups was $1,2,3,4,7$, $9,11,14,17,20,23,29,35,40,45,50,60,70,80$, and 90 day(s), respectively. The metasilicate in the samples (as dissolved metasilicic acid, $\mathrm{mg} / \mathrm{L}$ ) was determined using Silicon Molybdenum Yellow Spectrometry.

\subsection{Results and discussion}

The concentration of metasilicate in the clastic basalt, scoria, and soil immersion solutions all exhibit a progressive increase through time (Fig. 3). The rate for the clastic basalt immersion solution is the slowest, with the concentration of metasilicate reaching only 6.32 $\mathrm{mg} / \mathrm{L}$ by the $90^{\text {th }}$ day, whereas that in the scoria and soil immersion solutions reached 23.1 $\mathrm{mg} / \mathrm{L}$ and $15.2 \mathrm{mg} / \mathrm{L}$, respectively, by the same time. In terms of change of increase, the increasing rate of the concentration of metasilicate in basalt and scoria immersion solution is retarded in the later stage, whereas that for the soil immersion increases at a greater rate in the later stage of the experiment.

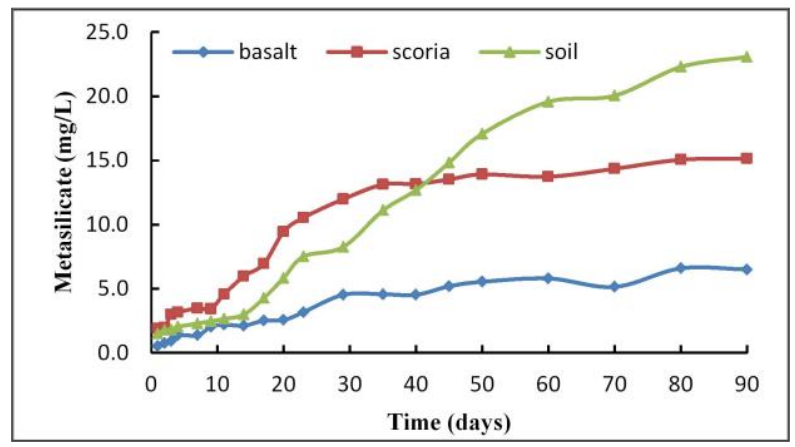

Fig. 3. The time development of metasilicate concentration in the clastic basalt, scoria and soil immersion solutions.

The scoria has a higher porosity, compared with basalts of the same particle size, which results in higher dissolution rate in the immersion solution. Electron microscopic scans of the scoria surface morphology before and after the immersion experiment show that a large number of tiny mineral particles having a rough morphology were observed adhering to the surface and the micropores of scoria before the immersion experiment. After immersion for 90 days, these tiny adhering particles were significantly reduced and a smooth the surface morphology generated. The scoria immersion solution simultaneously contains the dissolution of amorphous $\mathrm{SiO}_{2}$ as well as the hydrolysis of silicate and aluminosilicate. These results indicate that the contribution of soil and scoria to mineral water metasilicate is higher than that of clastic basalt under the same conditions. 


\section{Conclusions}

The metasilicate in mineral water of Jingyu County mainly comes from the lixiviation and hydrolysis reaction of $\mathrm{SiO}_{2}$ in basalt, scoria, and soil. Under laboratory conditions, the release of metasilicate from nubby basalt shows a linear pattern, and the steady release rate is about $0.01 \mathrm{mg} /(\mathrm{kg} \cdot$ day $)$. The soil and scoria are more likely to release metasilicate than basalt.

Acknowledgements. This work is supported by the National Natural Science Foundation of China (41572216), Special - Leading Technology Guide (SXGJQY2017-6) of the Provincial School Coconstruction Project, Shenyang Geological Survey Center project (121201007000150012) of China Geological Survey, and the Jilin Province Key Geological Foundation Projects (2014-13, 2018-11, 2018-13).

\section{References}

1. O. Bagdavadze, et al., Env. Geol. 54, 1301-1311(2008)

2. Y. Kopylova, G. Lepokurova, Doklady Earth. Sci. 436, 284-289 (2011)

3. F. Skopljak, T. Vlahovic, Environ Earth Sci. 66, 809-822(2012)

4. E. Dinellia et al., J. Geol. Exp. 107, 317-335(2010)

5. B. Yan, et al., Appl. Water Sci. 7, 1657-1667 (2017)

6. B. Yan, et al., Env. Geochem. Health 38, 291-307 (2016)

7. B. Yan, et al., Env. Earth Sci. 73, 4819-4829 (2015) 